\title{
Natural Language Processing and Computer Use in Social Work
}

\author{
Roger A. Lohmann \\ West Virginia University, roger.lohmann@mail.wvu.edu \\ Jay Wolvovsky
}

Follow this and additional works at: https://researchrepository.wvu.edu/faculty_publications

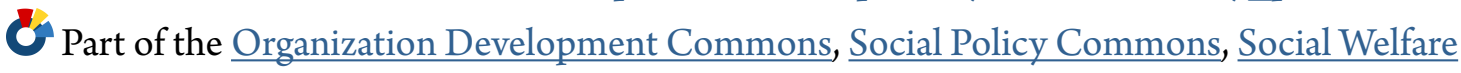
Commons, and the Social Work Commons

\section{Digital Commons Citation}

Lohmann, Roger A. and Wolvovsky, Jay, "Natural Language Processing and Computer Use in Social Work" (1979). Faculty Scholarship. 817.

https://researchrepository.wvu.edu/faculty_publications/817 


\title{
Natural Language Processing and Computer Use in Social Work ${ }^{1}$
}

\author{
Roger A. Lohmann²
}

and Jay Wolvovsky ${ }^{3}$

\section{Can Social Workers Do Computing?}

The care and feeding of computers have proven during the past decade to be a substantially more difficult problem for the human services than proponents had anticipated. Far from computers actually "doing social work" as some had feared and others had quietly hoped, the general response of the profession of social work could perhaps be characterized as one of benign disinterest. ${ }^{4}$ While commercial services as diverse as airline ticket sales, retail stores, insurance companies and hospitals have made expanding and ingenious use of computers for collecting, storing, retrieving and processing various types of information, social agencies have on the whole remained fairly aloof from the computer revolution except in certain clearly delineated areas. ${ }^{5}$

Several reasons account for this phenomenon (or, more accurately, for the lack of effects). For one thing, computers have been until quite recently very expensive to purchase and to operate. Thus, access in the human services has been restricted principally to those federal and state agencies with sufficient resources to support a computer installation. For another, the esoterica of computer programming skills have not been widely disseminated among educated publics, and the scarce resource of computer programming skill is, in practical terms, as unavailable to most social agencies today as expensive computer hardware. ${ }^{6}$ These factors and others of a similar nature lead one quite readily to the conclusion that the present distribution of computer technology in American society follows traditional lines of the distribution of power and wealth. (Although many might question whether, in this case, the computer is a boon or burden to the rich and powerful!)

\footnotetext{
${ }^{1}$ A revised version of this paper was published in Administration in Social Work. 3(4). December, 1979. 409-422.

${ }^{2}$ Associate Professor and Coordinator of Graduate Studies and Research. School of Social Work. West Virginia University.

${ }^{3}$ Research Associate. Office of Health Services Research. West Virginia University.

${ }^{4}$ For example, in an incident that was highly publicized locally, social workers resisted the efforts of a California Department of Social Welfare directive to place individual case records into a central computer. Loss of client confidentiality was cited as the major stumbling block. See "Social Workers Balk At Computers," San Francisco Chronicle, (July 16, 1968), p. 2.

${ }^{5}$ Most established computer use is for quantitatively-oriented Management Information Systems (MIS). See Samuel P. Bauer, "The Impact of Automation on Public Welfare Systems," Public Welfare, 31-1, (Winter, 1973), pp. 39-42. David W. Young, "Management information Systems in Child Care: An Agency Experience," Child Welfare, (February, 1974, pp. 102-111; and Elliot Rubin, "The Implementation of an Effective Computer System Social Casework, 57-7, (July, 1976, pp 438-444.

${ }^{6}$ This problem is often handled as a "neutral" question of the diffusion of technology. For a contrasting view, see Vol 1., No 1. Symbolic Interaction. (January, 1978).
} 
A separate and distinct line of argument can also be developed, however, tracing social work's disinterest in computers to other, non-economic factors. It can be argued that social workers in general have now shown any large-scale enthusiasm or interest in computing simply because computing has not yet adequately come to grips with the real or central information problems faced by most social work professionals. ${ }^{7}$ While computer technology involved in monitoring physiological functions of astronauts has had immediate applicability among earth bound patients, there have been no comparable measurement procedures of alienation, depression, isolation, morale, or other personal or social phenomena.

While computer science has developed largely inductively - from simple to complex and from the specifics of binary arithmetic to the increasingly sophisticated algorithms of support programs, most of this development has been entirely within the rigid boundaries of the quantitative, logically demanding parameters of information theory and computer science. Even the proponents of a technological art and music have made more technology than art!

Virtually all of the existing human service literature dealing with the impact, use and future potential of computing in the human services tends to adopt this quantitatively-based paradigm as natural, inevitable and necessary. In considerable degree, the advocates of computer usage in the human services have also been the advocates of quantitative measurement of process and outcome in service delivery and they have seldom been careful in delineating these two aspects of their interests. The few exceptions which can be found to this generalization tend to lapse into vagueness and visionary statements about the uses of artificial intelligence of the computer without really attending to any of the genuine problems such approaches raise. ${ }^{8}$

Without wishing to appear either contentious or presumptuous, we wish to propose in this article that a qualitatively-oriented paradigm which attends to procedures for storing, retrieving and manipulating information in the form of natural-language statements - the kind of utterances that human beings use in ordinary communication - is a highly appropriate but largely untapped resource for human services practice settings, and is increasingly supported by available software at numerous computer installations throughout the United States. Nothing in this article should be construed as either utopian or adventurous, since

\footnotetext{
${ }^{7}$ Theron K. Fuller, "Computer Utility in Social Work," Social Casework, 51-10, (December, 1970), pp. 606-611; Daniel M. Ogilvie, Philip J. Stone, Edwin S. Schnidman, "Some Characteristics of Genuine Verses Simulated Suicide Notes," in Stone, et. al., The General Enquirer: A Computer Approach to Content Analysis, Cambridge Mass.; MIT Press, 1966; Edwin J. Thomas, Claude L. Waiter and Kevin Flaherty, "Computer Assisted Assessment and Modification: Possibilities and Illustrative Data, Social Service Review, 48-2, (June, 1974), pp. 170-183; Ann M. Rothschild, "An Agency Evaluates Its Foster Home Service," Child Welfare, 53 (January, 1974), pp. 42-52.

${ }^{8}$ Harold Lewis, "Management in the Nonprofit Social Services Organization," Child Welfare, 54-9 (November, 1975), pp. 615-623; Judith C. Nelson, "Teaching Content of Early Field Work Conferences," iSocial Casework, 55-5, (March, 1974), pp. 147-153; William M. Lucianovic, :Human Service System," Journal of Systems Management, 3612, (December, 1975), pp. 37-44.
} 
all of the items to be discussed are several years behind the cutting edges of computer developments.

The following discussions are based upon the experiences of one of us with Coursewriter III, a computer assisted instruction (CAI) language developed by IBM, and various software components of the DEC-10 system at the University of Tennessee and our joint experiences with the WYLBUR text-editing system at West Virginia University. ${ }^{9}$

\section{Literature Review and Comments}

Among those who have broached the topic of computers in the published social work literature there is a wide spectrum of opinion on the applicability of this technology. Epitomizing one end of the continuum are those articles which caution the social work community on the threats and hazards involved in use of this technology. Such cautions seem to consist of two principal thrusts; one quite legitimate, the other a form of twentieth century Ludditism. ${ }^{10}$ On the one hand, there do, in fact, appear to be quite genuine threats to client confidentiality and a whole bevy of related problems of information control which arise in the automated data processing (ADP) context. ${ }^{11}$ On the other hand, the almost magical sense of awe and wonder one finds toward computers and data processing among some social workers appear the present at least completely unwarranted. It is well to caution such people that computers do not yet (and may never) "think" and the old maxim among data processors of "garbage in/garbage out" is as true as ever.

At the opposite extreme from these concerns with the threats and hazards have been a relatively few enthusiastic supporters of computer utilization who see great, indeed fantastic, opportunities to use computers as human surrogates in providing intake services and even counseling clients. ${ }^{12}$ With their potentials, it has been suggested, computers are the caseworkers of tomorrow! Implicit in such optimism (or cynicism depending on your point of view) is a utopian strain which must be

\footnotetext{
${ }^{9}$ Coursewriter and Wylbur are not languages or programs in the usual sense. They correspond more closely to software packages of procedures such as SAS, OSIRIS, or SPSS except with considerably greater flexibility.

${ }^{10}$ The Luddite movement during the English industrial revolution sought to prevent or forestall industrial development by physical destruction of machines. It is often cited as an ineffective response against technology.

${ }^{11}$ John H. Noble Jr., "Protecting the Public's Privacy in Computerized Health and Welfare Systems," Social Work, 16-1, (January, 1971), pp. 35-41; Gareth S. Hill, "Ethical Practices in the Computerization of Client Data: Implications for Social Work Practice and Record Keeping," NASW, new York, (June, 1971) (mimeographed). William J. Carran, Barbara Stearns and Honora Kaplan, "Privacy, Confidentiality and Other Legal Considerations in the Establishment of a Centralized Health-Data System, New England Journal of Medicine, 281-5, (July, 1969), pp. 243-244.

12 The title of Paul Abels' article "Can Computers Do Social Work?" Socil Work, 17-5, (Sept, 1972), pp5-11 has become a symbol of such views, although Abel's discussion is more temperate than the title might suggest. Also in this genre are: Gay Luce, "The Computer as Psychiatric Aid and Research Tool," Mental Health Program Reports, 2, Washington D.C. Department of Health, Education and Welfare (February, 1968); R.E. Smith, "Examination by Computer," Behavioral Science, 8-1 (January, 1963), pp. 76-79; and Kim Colby, James Wat and J.P. Gilbert, "A Computer Method of Psychotherapy" Journal of Nervous Disorders, 142, (February 1966) p. 150.
} 
seen as feeding some of the basic concerns which opponents of computerized futures so often express.

Somewhere near the center of the spectrum on this question are a small number of articles which take an admittedly short-range approach toward the future and seek to apply currently available computer technology to current organizations and programs in the human services. ${ }^{13}$

Most typically, these mid-range views have focused on the fundamental problem of the processing of management and decision-making information in agencies. Borrowing from business and industrial applications analysts in both public and voluntary human service sectors have, in recent years, outlined a number of interesting and provocative strategies for quantitatively-based systems for recording, classifying, monitoring and assessing agency and program performance.

Within the context of social work practice, such approaches as the pioneering management information systems (MIS) developed by the Office of Economic Opportunity in 1967, the MIS currently in use by the National Institute for Mental Health and its funded agencies, UWASIS-II (the second version of the United Way of America's Service Information System) and similar systems represent giant conceptual steps forward in the mundane task of organizing, collating and channeling useful information. ${ }^{14}$ The issue of the current effectiveness of these MIS systems notwithstanding, such numerically based systems can serve a useful, if pedestrian, role in overall agency management. ${ }^{15}$

It is at least plausible, however, that the overall usefulness of the kind of information generated and stored in such systems is rather distinctly circumscribed and limited in its applicability for human services. Specifically, such information is of greatest use for basic census and control purposes only. Other related issues of programmatic concern are either matters of relative indifference or ignored entirely in the present scheme of things. One may pose a number of quite sophisticated arguments or rationales for this condition: It is evidence of the overall transition from the muddy qualitative and process-oriented approaches of the past to the crisper, more rational approaches of management in the field.

Pressure from public and private funding sources has caused increased emphasis on measures of accountability that depend less on measures of the murky qualitative practice implications in favor of crisper forms of data. Front line workers are now feeling that the overreaction toward efficiency infringes on the processes

\footnotetext{
${ }^{13}$ H.R. Catherwood, "A Management information System for Social Services," Public Welfare, (Summer, 1974), 323, pp. 54-61. David W. Young, "Computerized Information Systems in Child Care: Techniques for Comparison, Child Welfare, 63-7, (July 1974), pp. 453-463; Jack H. Donhaue, Eliabeth Angell, Alyoysulj J. Baker, Judith Cingaiani, Marilyn Nelson and George Ross, The Social Service Information System, Child Welfare, 53-4, (April, 1974) pp. 243256.

${ }^{14}$ There is no presently available inventory or listing of the major MIS systems in the human services.

${ }^{15}$ The real outer limits of MIS systems are probably set by the limits of management decision making in an agency. Of the thousands of choices which must be made by agency staff daily, only a relatively small proportion can ever be singled out as "decisions for which standardized data can be collected.
} 
and people orientations that have been the basis of their previous training. The regimentation curtains their "artistic freedom" as it were.

In truth it would appear that the explanation is substantially simpler than that. Knowledge of and interest in computers is the human services has, until the present moment, been largely restricted to two classes of professionals: There are those whose background, training and credentials are in the quantitatively oriented system sciences and who entered human services for the explicit purpose of cleaning up all the messiness and sloppy qualitative thinking and solving the "welfare mess." At the same time, there are those whose principal exposure to the computer came in the form of batch-processing of bundles of IBM cards as part of a research project. In both cases, "computer" is associated with numerical manipulations and mathematical analysis of one form or another. Moreover, until quite recently (within the last decade, in fact) the objective limits of existing computer software meant that for all intents and purposes equating computers and mathematics was a practical reality. If, in fact, this condition had continued unabated the real future implications of the information revolution for social work would be straightforward: the usefulness of the computer would be directly linked to the ability to convert qualitative experience into quantitative data.

Fortunately, from our point of view at least, the computer revolution has proceeded far more rapidly than anyone in social work has given any sign of recognizing, and one of the foremost implications of recent developments has been the rapidly expanding capability of "the" computer as a qualitative, as well as quantitative instrument. We have all no doubt heard intimations of this for years especially how computers would soon be writing poetry, composing music, and writing novels. If present reality is examined closely, however, it appears less fantastic but more exciting.

The argument developed in the remainder of this article is that evolving computer technology has made dimensions of "using the computer" vastly simpler over the past decade, and also created enormous capacities for widespread use of computing equipment. In the present state of the art, virtually any child can make use of pre-programmed operations (witness the rapidly growing TV-gaming phenomenon) and any adult professional who is able to use a typewriter with any facility at all, demonstrate enough of a grasp of logic and information theory to create and maintain a set of personal files of the paper folder variety in a desk drawer, and speak any natural language should be able to master the rudiments of what we are calling natural language processing, and develop their own unique, individual solutions to their own information problems.

The basic elements of natural language processing as that term is used here are:

1) Use of a typewriter keyboard terminal to "interface" (or connect) a human operator and a time-sharing computer system. 
2) A text-editing or word processing system (that is, a set of canned programs which enable the user to enter, read, and edit data on one's own - rather than the computer's - terms. ${ }^{16}$

3) A file structure which allows the user relatively free reign with organizing, sorting, locating and disposing discrete items of information. The best analogy here is the recipe file box complete with index cards and tab dividers except that in natural language processing more than one set of dividers more than a single organizing principle can be used simultaneously in many operations.

4) Sufficient personal security and self-assurance to withstand the occasional necessary conversation or inquiry to bone fide computer programmers whose efforts to maintain the priestly secrecy and occult nature of their craft can, at times reach legendary proportions.

We take it to be axiomatic that the exponential growth of computer science has created a rapidly widening gap between those who are "into computers" and those who are not. We take it to be increasingly apparent as well, that one does not need to understand computers in any deeply technical sense in order to make use of them in the same way that one does not need to know the mechanics of internal combustion in order to drive an automobile. Unless one does have such an understanding, however, one must in dealing with computer programmers reconcile oneself to the contemporary version of the classic diver's complaint to the allknowing and uppity mechanic: “The do-jiggy doesn't sound right!" We confess to little more than an intuitive grasp of how computers actually work and virtually no interest in the matter as long as they continue to do so.

Nevertheless, it is essential to mention here several technical features critical to the present development of computer science and information theory which underlie present and future natural language potentials. The most fundamental of these, and familiar to all who have learned even the most basic computer programming is "string" processing, or the capability to treat a "string" of data or information (such as a sentence or a paragraph) as a single logical unit. It is safe to say that without string processing little if any of the more complex operations of computer science would be possible. Secondly, there is the development of increasingly high-speed computers able to handle discrete tasks at such incredible speeds as to create the illusion (for us pokey humans) of performing thousands of separate tasks for users simultaneously. Anyone who has never experienced the incredible response speeds of contemporary time-sharing computers literally cannot comprehend this phenomenon. ${ }^{17}$ Thirdly, one must accord some recognition to the technology of integrated circuits. Contemporary computer "chips" smaller than a human fingernail possess logical capacities far beyond those of the first room-sized

\footnotetext{
${ }^{16}$ On this point, see Lawrence K. Williams and Thomas M. Sodahl, "Comparing World Processing and Computers," Journal of Systems Management, 29-2 (February, 1978), pp. 9-11.

${ }^{17}$ Clifton Rucker, "Data Element and Text String Information," Journal of Systems Management, 29-1 (Janury, 1978), pp. 11-13.
} 
computers and are currently approaching the capabilities of present-day room-sized super computers. ${ }^{18}$ The principle impact of this trend is to make the prospect of a compact, economical desktop computer of enormous range and capacity a very real prospect. The critical aspect of present-day computer technology for natural language processing, however, is that one need spend little time praising the wonders of computer technology since for the most part the technology can simply be taken for granted in the way one takes graphite chemistry in the operation of a mechanical pencil or optics in the operation of a slide projector. The contemporary user is increasingly free to concentrate on the information problems at hand without the need to accommodate to the needs of the equipment.

\section{Qualitative Information Problems in Human Services}

What are those information problems for workers in human services contexts? According to contemporary discussions of information systems such functions as coding, storing, retrieving, modifying and destroying are basic to all information systems whether computerized or not. I may "code" a notation of a pending appointment ("R. Smith - 2 p.m.") store it (in my appointment book), check it later and discover a conflict, cross out the entry and write in 3 p.m. instead, or tear out the entire page. In the broadest sense, "information systems "of interest and relevance to the human services incorporate virtually all of the information flowing in professional communication. Case records, agency policy statements, board, staff and committee reports, memoranda, letters in and out of the agency, financial records, magnetic tapes of dictation, scratch pad notes, filling cabinets full of paper, appointment schedules, and - conceivably the "data' stored in individual memories as well. Indeed, information is the vey substance of communication and communication is the matrix upon which the social order of the agency is based. Clearly, some limits must be imposed however if one is to bring some order to the task of information system design. One conventional approach of information systems is to identify and improve the management information system; that is, the generally upward and central flow of information from the lowest to the highest levels of the organization and from the fringes to the center. ${ }^{19} \mathrm{~A}$ second conventional assumption is to accentuate the routine collection of numerical information. The aims of Natural Language Processing are, at this point, considerably less systematic and more modest than those of MIS proponents. We have assumed that for the foreseeable future face-to-face verbal encounters and written messages in conventional English must form the backbone of those communication systems which carry the greats traffic of messages. While MIS systems stressing rigorous definitions of data items, quantitative measurement and other features offer some prospect of an improvement in certain types of management-level decision making,

\footnotetext{
${ }^{18}$ One representative individual computer chip measuring .164 .222 inchies contains 6,200 transistors and is capable of executing 777, 000 instructions per second. Scientific American, 237-3 (September , 1977), p. 62.

${ }^{19}$ The September, 1977 issue of Scientific American is devoted to various scientific and technical perspectives on the microelectronics underlying these trends.
} 
MIS alone cannot be expected to offer a sufficiently flexible model to incorporate concern for non-management routine information tasks. Thus, when the uses of computers in social agencies are restricted to collecting management information, one should not be surprised at continued employee suspicion, resentment or even active opposition.

Briefly stated, Natural Language Processing endeavors to utilize electronic data processing equipment (principally word processing and text editing systems) to store and manipulate information with a minimum of coding, indexing and classification necessary. That is, to rely as heavily as possible on the natural language spoken and written by most adults in a society - in our case, English.

The aims of Natural Language Processing are, at this point, quite modest. Rather than projecting a radical transformation of the handling of routines, qualitative information in human service agencies, we believe that a more feasible approach is to proceed in a gradual, incremental manner to phase in computerassisted capabilities into the existing information flow of human service agencies. Indeed, this process is already well underway in many settings with the introduction of memory typewriters, letters coded on paper tape, etc. It is both conceptually and economically, a relatively small leap from such essentially clerical applications to increasingly sophisticated computer applications. For example, the typical memory typewriter at present can store from 20-50 letters or other comparable documents for automatic feedback on command. Interfacing such a typewriter with a full-scale computer device or even the type of cassette recorder used with present day home computers can provide for virtually limitless storage capacity.

Instead of storing 50 letters temporarily, one may have the potential for storing 50,000 letters or even 500,000 permanently - each of which can be called up and fully copied automatically on command. There is in this the potential to reduce all of the present-day filing cabinets full of carbon copies of letters to a relatively smaller set of magnetic tapes. ${ }^{20}$ More importantly what can be done for letters can be done for other information as well. Case records, for example. While much concern has been expressed over the very real threats to confidentiality posed by computerized records in enormous, centralized data banks, such approaches are no longer the only available option. ${ }^{21}$ Indeed, a memory typewriter with an auxiliary storage device capable of storing a worker's case load and even minimal security locks could actually improve on the confidentiality and security provisions of most present filing cabinet record systems. Further, the password security systems on present-day

\footnotetext{
${ }^{20}$ Management information systems, it bears repeating, are primarily for generation, processing and storing information relevant to management decisions. Not all communication and information handling in human service agencies is, or should be, management relevant.

${ }^{21}$ A number of mini computers use cassette recorders for tape storage devices, for example. Physical security of offline storage on cassette tape and current theoretical work on unbreakable codes" represent eh poles on this point. See Deborah Shapley, "The New Unbreakable Codes: Will They Put NSA Out of Business?" Washington Post. (July 9, 1978). B1.
} 
large-scale computer systems can foil all but the most sophisticated intruders handily.

In Natural Language Processing storage capacity is the first major consideration. To the extent that information can be stored in machine readable form the often costly and laborious process of storing and reproducing the information in suitable for can actually be improved upon.

A second major consideration which is currently possible in even the most basic of electronic information systems would be to circumvent a major portion of the tremendous volume of paper consumed in conveying information It is conceivable, for example, that in the near future an agency word processing system might be financed out of saved expenses for paper, duplication and copying. Assume, for example, that each worker in an agency had a memory typewriter and storage unit capable of storing a complete record of each case separately (let's say on ten cassette tapes). For reference purposes, the first file (or memory in memory typewriter jargon) could contain a listing of the location, file number and name for each case for reference purposes. Using our memory typewriter approach there would be extensive paper usage for each recall if the information had to be typed out on paper. With only a slight shift from the memory typewriter to a CRT (cathode ray terminal) that same worker could have the same access to the same information without the necessity of printing it on paper. The CRT is a television-like device capable of producing letters or graphic images simply with beams of light on a screen. A worker with such a terminal has functionally identical access to the same information without all the paper.

Each worker, therefore, might have a memory typewriter, auxiliary memory device and CRT screen. This could represent a considerable investment, however. A more economical solution would be to give each worker a CRT with memory device connected to a system or network capacity through which only those items which needed to be typed on paper could be "output" through the device. One way to create such a network would be to physically link all of the terminals in an office to a centrally available printer much as existing computer centers in universities and government offices do. With careful design the security problems inherent in such a system could be minimized or even eliminated. Such a system need not actually link individual machines into a physical network either. The system could simply consist of routine procedures for copying the materials to be printed onto a blank cassette tape and handling by the clerical staff, much as is presently done with dictation tapes.

If terminals are connected to a central printer, a further refinement on this same scheme should be possible, and that is to also connect these terminals to one another - thus creating an entirely new avenue for processing interoffice memos. Thus, Worker A can send a memo electronically to Worker B, or to all staff using such a "mailbag" approach. Each worker can then read the memo off the CRT screen and decide what to do with it - dispose of it by erasing it from the memory, store it with her other memos on a tape, write a reply, etc. 
When clerical staff are also plugged into such a system (as current thinking about word processing suggests they should be) a genuine revolution in office procedures may be in the making. (Provided, of course, that all office workers learn to type!) For example, a worker may wish to send the same memo to everyone in the office, plus written copies to several persons outside the office. The memo is then simply routed to all staff terminals, and to a secretary with special instructions for handling the printed copies. However, rather than transcribing the memo, as with dictation, the principal clerical function in this case becomes largely copy editing: Is the proper address information included? Are all the words spelled properly, etc.? After such editing is completed the secretary may merely release the memo to the printer and return the finished product to the author for signature.

To this point, however, we have addressed only slight extensions of the capabilities of existing memory typewriters. In order to realize the full potentials of Natural Language Processing, one must have an additional element ordinarily only available on full-scale computers; programming capability, or the ability to enter not only data but also instructions for performing predetermined logical operations on the data. Most memory typewriters (as well as pocket calculators) possess certain pre-established program steps which allow completion of certain routine functions (adding, subtracting, storing data in memory, etc.). In a full-scale computer, however, it becomes possible not only to create or enter new programming steps, but also to incorporate them into the data being stored. Perhaps an example will make this clearer: The typewriter on which this paper was typed will "record" images on paper corresponding to the keys punched. A memory typewriter will record those same images and reproduce them whenever a special recall key is pushed. With a full computer, one has capability not only for creating additional new functions, such as listing the number of lines typed or substituting words throughout the text, but to create complex series of steps to be performed in sequence (a program) and even to arrange those steps hierarchically and recursively.

The immediate practical significance of this for Natural Language Processing can be approached principally through the avenue of text editing programs which are - like all computer programs - sets of logical operations previously entered in the computer. In this case, a text editor is a program which allows the user to perform those logical operations most frequently encountered in dealing with any type of information: creating new images, erasing unwanted pieces of information, locating and adding to or subtracting from previous entries, moving words and sentences and even entire paragraphs to different locations. In addition to these common, simple tasks many existing text editing systems provide for some unexpected and highly useful functions. For example, for those accustomed to working with IBM cards, one of the most frustrating requirements is the constant need to completely start over and re-punch cards because mistakes cannot be corrected (punched out holes cannot be refilled!) In text editing programs, each line in a file corresponds to a physical IBM card, except that when a mistake is made, you can simply backspace and retype the correction. 
Further with text editing systems like Wylbur or SOS which are part of large computer systems, programs which are compiled with the text editor can often be run with a single command, thereby combining the memory typewriter and key punch functions into a single set of operations. Since our principal interest in natural language processing, however, is not with preparing and running statistical programs, other features of text editing are of greater interest. For example, in Wylbur there is the capability to automatically change line lengths. If a rough draft of a report was written with standard width typewriter margins, for example, and a decision was made to prepare the text on a 100-space width instead (perhaps to print it the other way on 8.5 " X 11 " paper, it is relatively simple to modify the width of all - or designated sections with a single command. Also, if for some reason, the draft of a text contains a repeated misspelling, the correction can be made at all of the points it occurs with a single entry.

This latter capability is closely related to another feature of the Wylbur text editor which is of great applicability. The same search feature which enables the user to identify and correct misspelled words can also be used in other ways. Assume that a worker has all active case records on files within a text editing system like Wylbur. It becomes a relatively easy task to search those files for specific items of information. For example, if the worker wants to know how many cases involve some alcohol problems, she might simply list all references to alcohol, drinking and other related key words. ${ }^{22}$ Such an approach could prove extremely useful in generating the kinds of data increasingly asked for on MIS reports today. Further, if the MIS report format is known and the worker has minimal programming ability with a language such as BASIC, it is relatively easy to write a program to automatically compile such information on an entire caseload.

Using a text editing system, it should be possible to incorporate at least three levels of information from qualitative, natural language records:

1. Direct, online storage and retrieval of information in case records, memoranda, agency policy and other documents.

2. Creation, storage and use of "self-manipulating" program files.

3. Creation, storage and use of "master files" which perform operations at different times on changing information files.

\section{Direct Storage}

In probing other, more esoteric aspects of computer science, the earlier automated data processing capacity of such equipment seems to have been ignored. The amount of information relative to space which can be stored using a wordprocessing computer system, plus the relative ease of access in the well-designed system, however, makes this still a viable (and increasingly economical) option. Such simple storage (involving no higher-level programming whatsoever) is a major element of Natural Language Processing and may incorporate any or all agency

\footnotetext{
${ }^{22}$ See articles in Stone, et. al., General Inquirer.
} 
documents - case records, minutes of meetings, memoranda, job descriptions, agency policy statements, even standard boiler plate items included in grant applications. In such direct storage uses, the computer's various memory devices become a substitute for information "stored" on handwritten and typewritten paper.

\section{Self-Manipulating Program Files}

Anyone who has ever worked with BASIC language programming is familiar with this approach, in which information is stored together with certain predetermined programming instructions for in some way manipulating the information on command. For example, the program to enable the worker to check on this monthly. Or the program could be written so that the worker is asked to insert the specific problem which the program then searches for. In either case the data and the instructions are stored together and periodically run.

\section{Master Files}

A variant on this type of activity is a set of programming steps which are stored separately, and which in some respect control or regulate certain activities without the need for conscious intervention. Thus, a master list scheduling program might be created which automatically listed the day's appointments on a worker's terminal file each morning and reported adjusted information based on worker reports of non-filled appointments to accounting at the end of each day.

\section{Simplicity}

Finally, one of the principal considerations favoring the widespread adoption of word processing, text editing, and other yet-to-be devised Natural Language Processing approaches is the relative simplicity involved. Until quite recently, one of the hallmarks of work with computers - in addition to the reputed need to understand what was going on technically - was the need for rather extensive and elaborate program training. It may require dozens of hours of intensive study and work, at a minimum, to learn to work the Fortran, BSIC, COBOL or such simple programming systems as SPSS and SAS. However, virtually anyone who can type, remember a few basic self-evident commands can learn to work with a text editing system in a matter of hours. Further, in the case where a number of workers are linked with one another a good deal of natural creativity and curiosity can be expected to produce usable results. For example, with our present Wylbur set-up, the junior author had been working with the system for only a few hours when he devised an internal memo system for passing messages. While it will still be necessary in many instances to have sophisticated technical assistance for solutions to some problems, the Natural Language Processing approach accentuates the simple rather than the esoteric, aspects of computer utilization.

\section{Summary}


Natural Language Processing is a term of art used her to focus attention on the continued and rapidly expanding suitability of computers and automated data processing equipment for use with the kinds of essentially qualitative information processing tasks which continue to form the critical core of information handling in human service organizations. Use of the concept of Natural Language Processing in this case is strategic to highlight the increasingly apparent linkages between the word processing concern of those dealing with office management and secretarial work, and the text editing capabilities of computer systems such as Wylbur and SOS.

Our reading of present trends is that Natural language Processing poses a generally positive and optimistic answer to the question posed at the beginning of this article: Can social workers do computing? The answer can be yes, provided supports and capabilities of computer systems are tailored toward the real informational needs of human services professionals, rather than only seeking redesign of their work to fit the alleged requirements of the equipment. 


\section{Afterword (2019)}

It has been said that in the earliest days of the automobile, scouts were required to walk ahead of the vehicle to warn those driving horses of the approaching machines. Reading this article today has something of that feeling about it. In looking back forty years, one of the things that is most striking is the sheer, astonishing degree of change wrought over that time; things that we thought required extended explanation now seem the simplest of taken-for-granted realities.

Generations of information workers who have come along since that time probably have no awareness of the role that carbon paper and carbon copies once played in the typical office or school and how recently they were still in regular use. When his article was first written in late 1978 it was still three years before the IBM desktop computer, with its MS-DOS software began the personal computing revolution, and five years before the Macintosh introduced to mass audiences the mouse, variable type sizes and fonts and dot matrix printers and almost ten years before affordable laser printers. This article preceded by several years the availability of spreadsheet software for desktop computers.

When we wrote this both Jay, who went on to a career as a health care administrator in Maryland, and I were already convinced that great changes were in the wind. At the time, I had known about the email systems of ARPANET and for almost a decade from friends whose work on government contracting gave them access. I had even done some experimenting of my own with the email features of the DEC-10 system at the University of Tennessee and BITNET when we moved to West Virginia University. I was also at the time serving as a qualitatively oriented advocate on the campus computing committee, along with a psychologist. We joined a lot of STEM (Science, Technology, Engineering and Mathematics) types whose attitude toward the viewpoint expressed in this article might best be described as bemused curiosity and skepticism. They knew that computers were for computation but were highly skeptical that they might have some other applications of the type discussed here. (Obviously, they have long since seen the light!)

In the decades after this piece was published, what we called Natural Language Processing went far beyond anything we were imagining for it in 1979 and grew up to include not only word processing and email, but also what are now known as social media, as well as Wikipedia and all of the derivative online encyclopedias, and the various forms of computer-based qualitative research software, and so much more.

Although they seem very minor points today, perhaps our greatest misreadings of the future was the reliance we expected to place on future time-sharing systems 
and our complete failure to comprehend the significance of what later became known as "Murphy's Law", which of course made it not only possible but also economical for fantastically greater levels of usage very little need for continued "time sharing."

The research repository where this manuscript is stored is in important respects a descendant of the memory typewriter storage discussed in the text. Roughly a decade after this article was published, in 1990, I founded an email discussion list for members of ARNOVA and those interested in nonprofit research which is still in operation as of this writing. For most of the 29 years since its founding, the list has been archived and the readily searchable thousands of messages sent on the list correspond closely to the Natural Language Processing systems described here. 